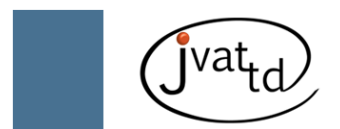

\title{
Circadian pattern of Bothrops moojeni in captivity (Serpentes: Viperidae)
}

\author{
Stuginski DR (1, 2), Sant'Anna SS (2), Fernandes W (2), Abe AS (3)
}

(1) Department of Physiology, Bioscience Institute, University of São Paulo (USP), São Paulo, São Paulo State, Brazil; (2) Laboratory of Herpetology, Butantan Institute, São Paulo, São Paulo State, Brazil; (3) Department of Zoology, São Paulo State University (UNESP - Univ Estadual Paulista), Rio Claro, São Paulo State, Brazil.

\begin{abstract}
Members of the subfamily Crotalinae are considered to be essentially nocturnal and most of the data about these snakes have been collected from the field. Information on how nutritional status affects the movement rate and activity patterns is a key point to elucidating the ecophysiology of snakes. In this study, we distributed 28 lancehead Bothrops moojeni into three groups under distinct feeding regimens after a month of fasting. Groups were divided as follows: ingestion of meals weighing (A) $40 \%$, (B) $20 \%$, or (C) $10 \%$ of the snake body mass. Groups were monitored for five days before and after food intake and the activity periods and movement rates were recorded. Our results show that $B$. moojeni is prevalently nocturnal, and the activity peak occurs in the first three hours of the scotophase. After feeding, a significant decrease in activity levels in groups $A$ and $B$ was detected. The current results corroborate previous field data that describe $B$. moojeni as a nocturnal species with low movement rates. The relationship between motion and the amount of food consumed by the snake may be associated with its hunting strategy.
\end{abstract}

Key words: Bothrops moojeni, snake activity, post-prandial, circadian rhythms, captivity.

\section{INTRODUCTION}

Activity patterns in snakes have been an interesting object of study over the years (1-5). Snakes essentially move in search of food, mates, shelter, hibernacula, or even new habitats (6-8). A number of activity patterns are described in snakes, from the extremely active species to those that tend to remain static to save energy while ambushing a prey (9-13). Movements and activity in snakes can vary depending on the seasonal climate, age, physiological state, geographic location and other variables $(12,14-16)$.

Snakes are roughly classified into diurnal and nocturnal species according to their periods of activity. On the other hand, activity periods are poorly defined, as some snakes are active in both diurnal and nocturnal phases, while others are essentially crepuscular and some may even show different activity patterns across the seasons $(14,17)$.

Assessment in the wild of the activity period of species within the genus Bothrops (sensu lato) indicates a tendency toward nocturnal and crepuscular patterns (18). Such snakes typically use a "mobile ambush" strategy, moving around until they find a suitable place to ambush their prey, although some species of the genus have been observed actively foraging (19-22). Snakes of the genus Bothrops (sensu lato) can handle relatively large prey items, taken in the form of massive meals, but with a low feeding frequency (22). The increase in the snakes' body mass after eating a large prey can negatively affect the movement rates of these animals, thus impacting many of their activities. In spite of the importance of this consideration for understanding the activity of snakes, little information is available from 
field studies, as there are inherent difficulties in assessing the food intake in a precise manner.

The aims of the present work were to test the hypothesis that Bothrops moojeni is a nocturnal animal and to evaluate the influence of the meal size on the movement rates of this species in captivity.

\section{MATERIAL AND METHODS}

\section{Animals and Maintenance}

The study was carried out on 28 captivity-born Bothrops moojeni $(178.1 \pm 40.3 \mathrm{~g})$, of both genders, aged one to two years, from the Laboratory of Herpetology, Butantan Institute. Animals were housed individually in plastic cages measuring $45 \times 30 \times 20 \mathrm{~cm}$ (length $\times$ width $\times$ height), with cardboard as substrate. The temperature was kept between 23 and $27^{\circ} \mathrm{C}$, and the humidity between 56 and $70 \%$. The animals were fed mice once a month (Mus musculus). The experiment was conducted for ten months from January 2009 to October 2009.

\section{Experimental Protocol}

The photoperiod in the experimental room was controlled at 12:12 hours (photophase: scotophase) and the relative humidity inside the room was kept between 56 and 70\% throughout the experiment. During the experiments each snake was placed individually in an arena after a previous one-month fasting period. For the first 48 hours the animals were left without monitoring so that they could become familiar with the experimental setup. After that, for the next nine days (four days fasting and five days post-prandial), the animals were videomonitored. Three feeding groups were established: A, B and C, which consumed respective amounts of food equivalent to $40.6 \pm 2.0 \%, 20.3 \pm 1.98 \%$ and $10 \pm 1.8 \%$ of their own body weight.

\section{Thermic Arena}

The arena dimensions were $150 \times 30 \times 80$ $\mathrm{cm}$ (length $\mathrm{x}$ width $\mathrm{x}$ height) and it was lined with oven-sterilized soil as substrate. Ovensterilization was performed at $130^{\circ} \mathrm{C}$ for six hours. A temperature gradient ranging from $36^{\circ} \mathrm{C}$ to $17^{\circ} \mathrm{C}\left( \pm 2^{\circ} \mathrm{C}\right)$ was framed in the arena, putting a 150 watt electric heater as a hot spot on one side of the arena and a Coel chiller (Brazil) as a cold spot on the opposite side, thereby maintaining a controlled temperature range throughout the experiment. In order to better situate the position of the snake within the arena, its floor was divided into 20 square areas $(15 \times 15 \mathrm{~cm})$ delimited by strings placed directly over the surface (Figure 1).

\section{Imaging}

Movement monitoring was supported by a webcam equipped with infrared LEDs. Images were automatically captured every 60 seconds via HSSVSS 6.06 freeware. In our analysis, we considered a movement to have occurred when a snake shifted its location to another square. Slight movements without transposing a quadrant's limits were not taken into account. The whole time of activity was computed and data were analyzed using GraphPad InStat5 software (GraphPad Software, Inc., USA).

\section{Data Analysis and Statistics}

The activity time and the relationship between prandial status and movement rates were tested by the Dunn and Bonferoni tests. A $p$-value < 0.05 was considered statistically significant.

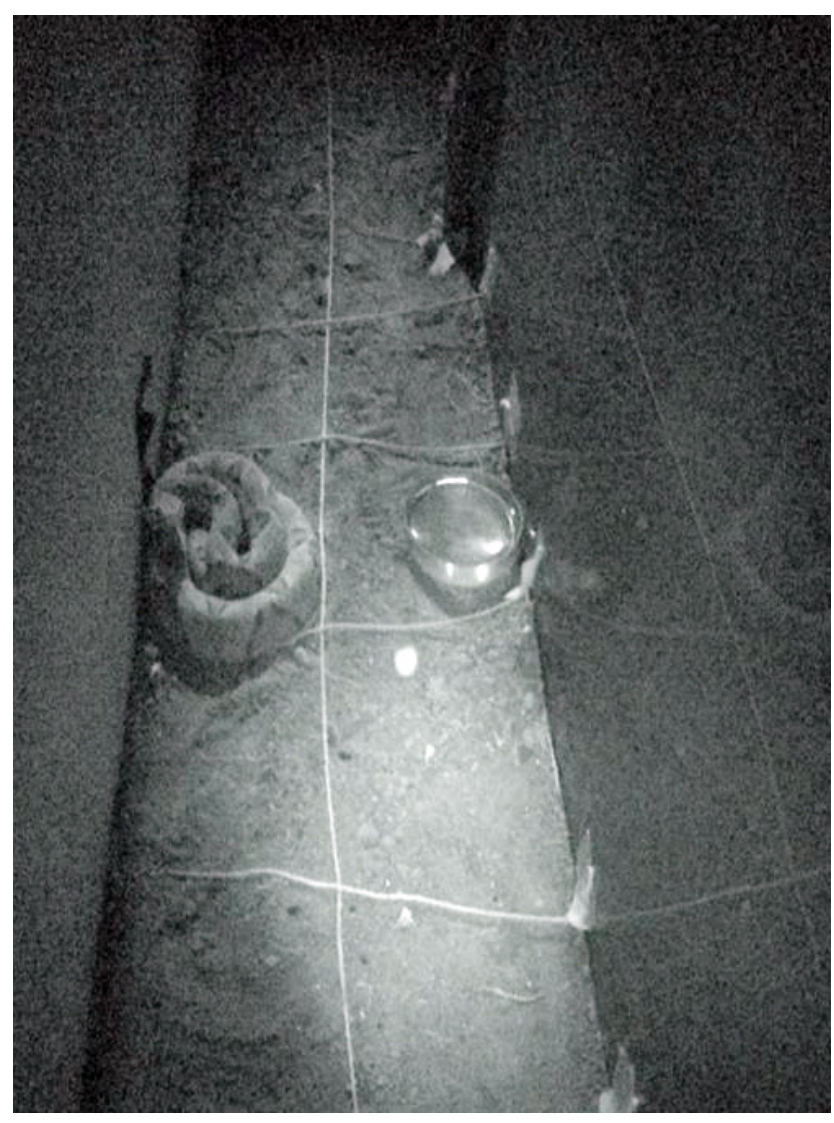

Figure 1. Arena during scotophase. 


\section{RESULTS}

During the experiment approximately de 363,000 images were analyzed to determine the transit rates of the animals.

Due to the absence of difference in the movement rates and activity times between males and females $(p>0.05)$, data from both genders were pooled for the analysis. The activity pattern was predominately nocturnal in both fasting and fed snakes, with $97.36 \%$ of all recorded movements occurring during the scotophase. The activity peak occurred in the first quarter of the scotophase, between 18:00 and 21:00 hours $(\mathrm{p}<0.001)$. A decreasing pattern was registered starting from this point. We still detected a significant increase in the movement frequency in the second and third quarters in comparison to the photophase $(\mathrm{p}<0.001)$, but found a significant decrease in the time spent in motion during the second quarter when compared to the first one $(p<0.01)$ and during the third quarter when compared to the second $(p<0.001)$. In the fourth quarter we observed some movements, but no significant difference was detected in comparison to the photophase, when movements almost ceased ( $p>0.05)$ (Figure 2).

As to the post-prandial condition, group A showed a significant decrease in the movement rate for four days in the first half of the scotophase, versus the fasting rate $(p<0.05)$. Group B showed a decrease in movement rates during the first quarter of the activity time for three days ( $\mathrm{p}<$ 0.05). Movement rates did not differ significantly between group $\mathrm{C}$ and fasting animals during the experiment $(p>0.05)$ (Figure 3$)$. All the feeding groups maintained a nocturnal activity pattern and no difference between fed and fasting snakes was detected during the photophase ( $p>0.05)$.

\section{DISCUSSION}

Based on data from field work, Nogueira et al. (23) described Bothrops moojeni as an essentially nocturnal species according to its activity pattern, as well as other species of the genus on which information is available (22, 24-26). Our results with $B$. moojeni are in concordance with the pattern of nocturnal activity previously reported in field studies, indicating that the activity pattern remains unchanged for snakes in captivity. The highest observed activity period of $B$. moojeni in the first hours of the scotophase agrees with results obtained for Bothrops atrox in the field. B. atrox is a closely related species whose activity also peaks in the first half of the night (24).

The overlapping of the activity period of predators and their prey is a common feature of many snake species, especially low-mobility ones $(11,27,28)$. Although Bothrops moojeni feeds on a wide range of prey, the contribution of different items varies ontogenetically $(22,23,29,30)$. In

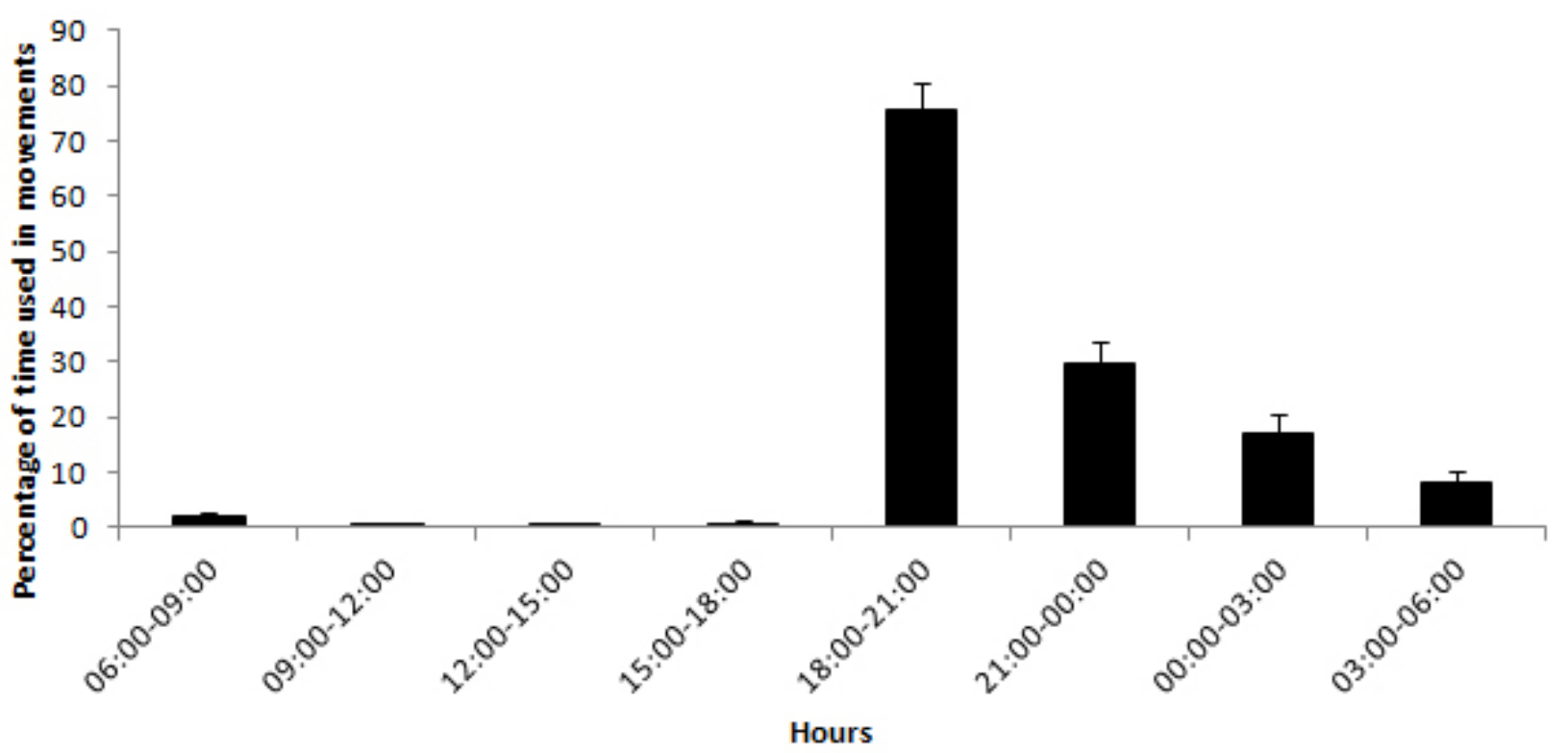

Figure 2. Differences in activity pattern during photophase and scotophase. Note that the peak of activity occur during the first quarter of the scotophase. 

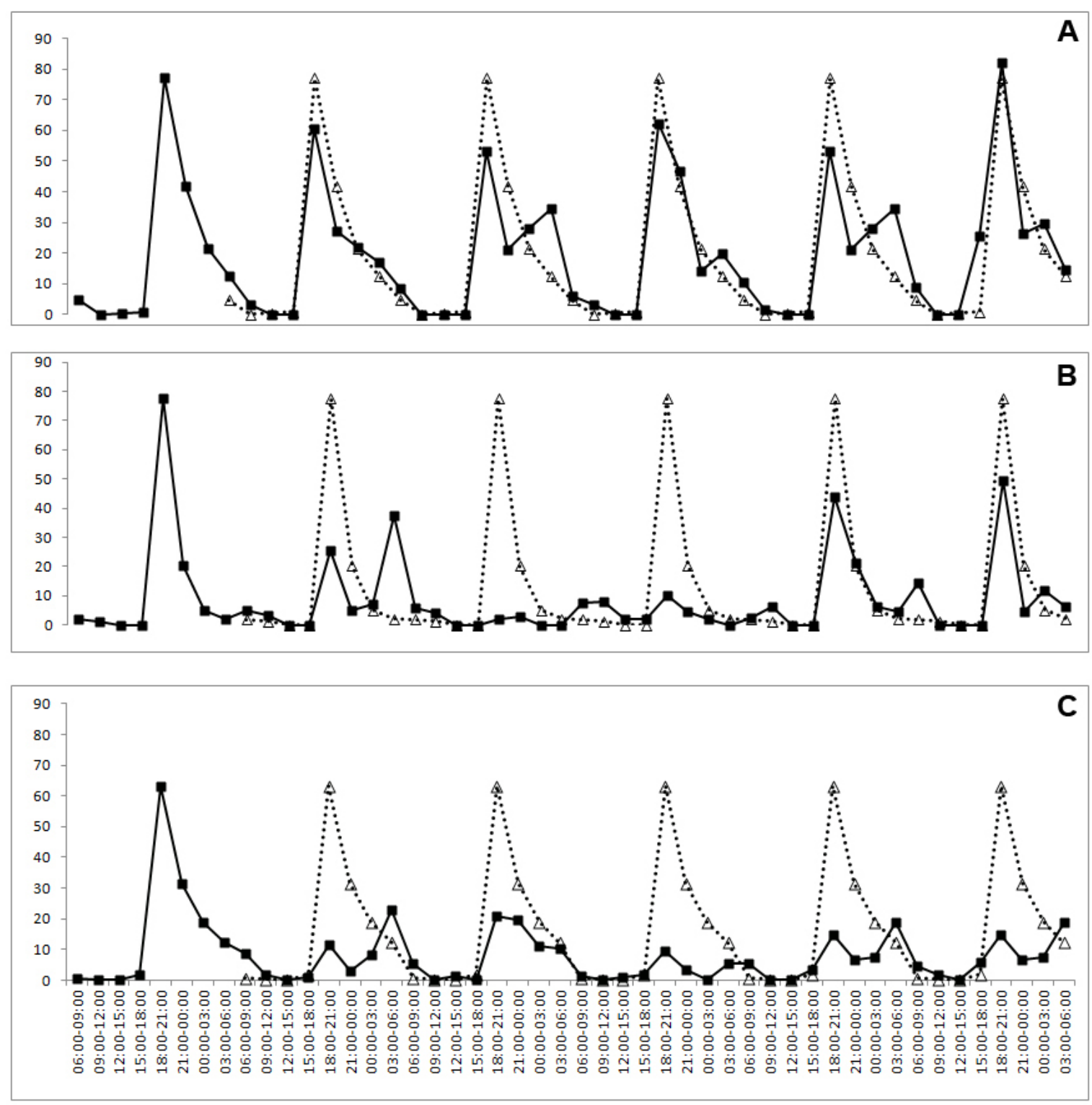

Figure 3. The difference in movement rates after feeding. Letters $\mathbf{A}, \mathbf{B}$ and $\mathbf{C}$ in the figure present movement rates of animals that ingested 10,20 and $40 \%$ of their own body weight, respectively.

this case, the diet variability in Bothrops moojeni could have an effect on the activity periods because different prey may present distinct active hours (18). In our study, the absence of a significant difference in the activity pattern in an inter-individual comparison may be a reflection of the size homogeneity among the snakes used, irrespective of gender. The alimentary items for both males and females of the same size are similar (23), supporting the theory that the activity periods of animals of the same size may overlap, with gender not being an influencing variable.

Although the alimentary condition did not alter the activity period, the amount of food intake influenced the movement rate. This finding suggests that the role of post-prandial movements may diverge from those observed in the preprandial condition. The movement diminution of snakes that consumed greater amounts of food may be related to satiety, while the maintenance of the movement rate among group $\mathrm{C}$ snakes may represent a continual search for food. However, it is difficult to take this conclusion from our data given the other factors that could be related to inter-group differences including dislocation cost, thermophilic behavior and thermogenesis $(31,32)$.

The great increase in the metabolic rates during digestion and the slight rise in the total mass to 
be moved may impact the energy expenditures of movements and/or in predation costs due to a lesser body agility $(33,34)$. In this scenario, the decrease in the movement rates could be more related to a physiological restriction than just a reflection of satiation. The continuous movement observed in the snakes that had a food intake corresponding to $10 \%$ of their own body mass indicates that this elevation in body mass does not significantly influence the movement rates. A similar dynamic can be observed in most snakes with high activity, e.g., diurnal colubroid snakes, which usually consume meals corresponding to $10 \%$ or less of their own body mass. The observed ingestion of large meals by $B$. moojeni, in addition to the subsequent decrease in its ability and/or necessity to maintain the fasting movement rates seems to be a reflection of the ecophysiological strategies of this animal. In this context, the apparent decreased mobility after a large meal may be just a "minor price to pay" for cryptic snakes that ambush with a low metabolism such as Bothrops moojeni.

\section{CONCLUSIONS}

Bothrops moojeni display a more nocturnal pattern of activity when in captivity. As also noted in field observations, the movement peak occurs in the first quarter of the scotophase, with rare movements occurring in the photophase. This pattern is not influenced by the feeding status and it appears to be conserved among other related Bothrops. On the other hand, meal size does act upon the movement rates, which are significantly decreased in snakes that take relatively large meals.

The factors associated with movement and activities of snakes are quite complex and diversified. For this reason, a number of variables act in a synergistic manner to promote responses that vary according to environmental, ontogenetic or seasonal climate influences. Further studies are required to assess other factors influencing the activity time and movement rates of snakes. Such studies would certainly contribute to ascertaining a more complete panorama of this ecological trait.

\section{ACKNOWLEDGEMENTS}

The authors are thankful to Ana Helena Pagotto for her assistance.

\section{COPYRIGHT}

(C) CEVAP 2012

\section{SUBMISSION STATUS}

Received: July 8, 2011.

Accepted: August 8, 2011.

Abstract published online: September 12, 2011.

Full paper published online: February 28, 2012.

\section{CONFLICTS OF INTEREST}

The authors declare no conflicts of interest.

\section{FINANCIAL SOURCE}

The State of São Paulo Research Foundation (FAPESP) provided the financial grants.

\section{ETHICS COMMITTEE APPROVAL}

The present study was approved by the Ethics Committee on Animal Use of the Butantan Institute (protocol n. 334/06). In addition, the experiments followed the protocols of the Brazilian Society of Laboratory Animal Science (SBCAL/COBEA).

\section{CORRESPONDENCE TO}

Daniel Rodrigues Stuginski, Instituto Butantan, Rua Alvarenga 1275, ap. 24A, São Paulo, SP, 05509-002, Brasil. Phone: +55 1125075744. Email: dstuginski@yahoo.com.br.

\section{REFERENCES}

1. Gibbons JW, Semlitsch RD. Activity patterns. In: Seigel RA, Collins JT, Novak SS, editors. Snakes: ecology and evolutionary biology. New York: MacMillan Publishing Company; 1987. p. 326-421.

2. Reinert HK. Radiotelemetric field studies of pitvipers: data acquisition and analysis. In: Campbell HK, Brodie ED, editors. Biology of Pitvipers. Tyler; 1992. p. $185-98$.

3. Houston D. Movements and activity patterns of Arafura filesnakes (Serpentes: Acrochordidae) in Tropical Australia. Herpetologica. 1994;50(3):349-57.

4. Sun LX, Shine R, Zhao D, Zhengren T. Biotic and abiotic influences on activity patterns of insular pitvipers (Gloydius shedaoensis, Viperidae) from northeastern China. Biol Conserv. 2000;97(2001):387-98.

5. Webb JK, Shine R. A field study of spatial ecology and movements of threatened snake species, Hoplocephalus bungaroides. Biol Conserv. 1997;82(2)203-17.

6. Larsen K. Movements and behavior of migratory garter snakes, Thamnophis sirtalis. Can J Zool. 1987;65(9):2241-7.

7. Macartney JM, Gregory PT, Larsen KW. A tabular survey of data on movements and home ranges of snakes. J Herpetology. 1988;22(1):61-73. 
8. Bonnet $\mathrm{X}$, Naulleau G, Shine R. The dangers of leaving home: dispersal and mortality in snakes. Biol Conserv.1999;89(1):39-50.

9. Slip DJ, Shine R. Habitat use, movements and activity patterns of free-ranging diamond pythons, Morelia s. spilota (Serpentes:Boidae): a radiotelemetric study. Wildlife Res. 1988;15(5):515-31.

10. Shine R, Fitzgerald M. Large snakes in a mosaic rural landscape: the ecology of carpet pythons Morelia spilota (Serpentes: Pythonidae) in coastal eastern. Biol Conserv. 1996;76(2):113-22.

11. Downes S, Shine R. Sedentary snakes and gullible geckos: predator-prey coevolution in nocturnal rockdwelling reptiles. Anim Behav. 1998;55(5):1373-85.

12. Whitaker PB, Shine R. A radiotelemetric study of movements and shelter-site selection by free-ranging brown snakes (Pseudonaja textilis, Elapidae). Herpetol Monogr. 2003;17:130-44.

13. Shine R, Sun L, Fitzgerald M, Kearney M. A radiotelemetric study of movements and thermal biology of insular Chinese pit-vipers (Gloydius shedaoensis, Viperidae), Oikos. 2003;100:342-52.

14. Shine R. Activity pattern in Australian elapid snake (Squamata: Serpentes: Elapidae). Herpetologica. 1979;35(1):1-11.

15. Secor SM. Ecological significance of movements and activity range for the sidewinder, Crotalus cerastes. Copeia. 1994;3:631-45.

16. Daltry JC, Ross T, Thorpe RS, Wuster W. Evidence that humidity influences snake activity patterns: a field study of the Malayan pit viper Calloselasma rhodostoma. Ecography. 1998;21(1):25-34.

17. Shine R, Lambeck R. A radiotelemetric study of movements, thermorregulation and habitat utilization of Arafura filesnake (Serpentes: Acrochordidae). Herpetologica. 1985;41(3):351-61.

18. Hartmann PA, Teresinha M, Olímpio L, Giasson M. Uso do habitat e alimentação em juvenis de Bothrops jararaca (Serpentes: Viperidae) na Mata Atlântica do Sudeste do Brasil. Phyllomedusa. 2003;2(1):35-41.

19. Sazima I. Comportamento alimentar da jararaca, Bothrops jararaca: encontros provocados na natureza. Cienc Cult.1989;41:500-5.

20. Sazima I. Caudal luring in two Neotropical pitvipers Bothrops jararaca and B. jararacussu. Copeia. 1991;1:245-8.

21. Egler SG, Oliveira ME, Martins M. Bothrops atrox (Common Lancehead), Foraging behavior and ophiophagy. Herpetol Rev. 1996;27(1):22-3.
22. Martins M, Marques OAV, Sazima I. Ecological and phylogenetic correlates of feeding habits in Neotropical pitvipers (genus Bothrops). In: Schuett GW, Hoggren M, Douglas ME, Greene HW, editors. Biology of the Vipers. Eagle Mountain: Eagle Mountain Publishing. 2002. p. 307-28

23. Nogueira C, Sawaya RJ, Martins M. Ecology of the pitviper, Bothrops moojeni, in the Brazilian Cerrado. J Herpetol. 2003;(37)4:653-9.

24. Oliveira ME, Martins M. When and where to find a pitviper: activity patterns and habitat use of the lancehead Bothrops atrox in central Amazonia, Brazil. Herpetol Nat Hist. 2001;8(2):101-10.

25. Campbell JA, Lamar WW. Lanceheads, Genus Bothrops Wagler, 1824. In Campbell JA, Lamar WW. Venomous of the western hemisphere. New York: Cornell University Press. 2004. p. 334-401.

26. Pereira da Cruz JG. Ritmo circadiano e atividade locomotora em Bothrops jararacussu (Serpentes: Viperidae). Biotemas. 2007;20:(3):55-61.

27. Mori A, Toda M, Ota H. (2002). Winter activity of Ovophis okinavensis in the humid subtropics: foraging on breeding frogs under cool temperature. In: Schuett GW, Hoggren M, Douglas ME, Greene HW. editors. Biology of the Vipers. Eagle Mountain, UT: Eagle Mountain Publishing. 2002. p. 329-44.

28. Creer S, Chou W, Malhotra A, Thorpe RS. Offshore insular variation in the diet of the Taiwanese bamboo viper Trimeresurus stejnegeri (Schimidt). Zool Sci. 2002;19(8):907-13.

29. Martins M, Gordo M. Bothrops atrox (Common Lancehead), Diet. Herpetol Rev. 1993; 24:151-2.

30. Martins M, Oliveira ME. Natural history of snakes in forests of the Manaus Region, Central Amazonia, Brazil. Herpetol Nat Hist .1996;6(2):78-150.

31. Tattersall GJ, Milson WK, Abe AS, Brito SP, Andrade DV. The thermogenesis of digestion in rattlesnakes. J Exp Biol. 2004;207: 579-85.

32. Stuginski DR, Fernandes W, Tattersall GJ, Abe AS. Thermogenesis in Bothrops moojeni (Serpentes: Viperidae). J Venom Anim Toxins incl Trop Dis. 2011;17(3):287-92.

33. Sievert LM, Andreadis. Specific dynamic action and postprandial thermophily in juvenile northern water snakes, Nerodia sipedon. J Therm Biol. 1999;24(1):515.

34. Toledo LF, Abe AS, Andrade DV. Temperature and meal size effects on the postprandial metabolism and energetics in a boid snake. Physiol Biochem Zool. 2003. 76(2):240-6. 